\title{
Successful Early Clozapine Trial in the Treatment of First-episode Schizophrenia: A Case Report
}

\author{
Yeon-Jin Kim, Seung-Ho No, Sang-Yeol Lee \\ Department of Psychiatry, Wonkwang University School of Medicine, Iksan, Korea
}

Clozapine remains the treatment of choice in refractory schizophrenia despite its various requirement to prescribe, such as mandatory blood monitoring program and various metabolic complication. Currently, clozapine is recommended only after two failed adequate antipsychotics trials. We report a case of a successful early clozapine trial in the treatment of first-episode schizophrenia patient, considering poor treatment response and repeated self-injurious behavior. This case highlights the efficacy of an early clozapine trial as a second-line treatment for first-episode schizophrenia in contrast to switching or combination treatment strategy.

KEY WORDS: Clozapine; First-episode schizophrenia; Antipsychotics.

\section{INTRODUCTION}

Despite the introduction of several new atypical antipsychotic drugs over the past two decades, clozapine remains the treatment of choice in refractory schizophrenia. The rationale for prescribing clozapine for treatment-naive schizophrenia rests on various guidelines. ${ }^{1)}$ However, given that clozapine requires mandatory blood monitoring ${ }^{2)}$ and has several potential metabolic complications, including diabetes, hyperlipidemia, and cardiovascular risks, ${ }^{3)}$ most clinical guidelines and 'real world' treatment settings have placed restrictions on the use of the drug.

Currently, clozapine is recommended only after an incomplete response to two adequate trials of other antipsychotic medications. For example, in Canada, clozapine can be prescribed only as a third-line treatment. Current evidence does not support this position; however, limited data and methodological issues preclude a firm conclusion. ${ }^{4)}$ Moreover, in the case of fist-episode psychosis, clozapine may be preferable in the inpatient setting to limit early clinical and cognitive deterioration. ${ }^{5)}$ Response rates close to $90 \%$ have been reported in first-epi-

\footnotetext{
Received: October 2, 2013 / Revised: October 31, 2013

Accepted: November 7, 2013

Address for correspondence: Sang-Yeol Lee, MD, PhD

Department of Psychiatry, Wonkwang University School of

Medicine, 895 Muwang-ro, Iksan 570-711, Korea

Tel: +82-63-859-1044, Fax: +82-63-857-1043

E-mail: psysangyeol@hanmail.net
}

sode schizophrenia; ${ }^{6}$ however, response rates markedly drop in patients who require a second trial and decrease further with subsequent trials. ${ }^{4)}$ The benefits of clozapine as a second-line treatment must be investigated in terms of the likelihood of earlier remission and transition to good social functioning. Here, we report a case that demonstrates the efficacy of an early clozapine trial as a second-line treatment for first-episode schizophrenia in contrast to switching to another atypical antipsychotic or combination treatment.

\section{CASE}

A 31-year-old man with no history of drug or alcohol use, was brought to the hospital by his parents and police. He had no history of psychiatric treatment or significant medical illness. He had good marks in high school, but he had been shy and reserved throughout his life. His mother had been treated for longstanding psychotic depression.

The patient studied education at college, but failed the certification exam three years in a row. He worked as a school instructor for several months; however, his parents wanted him to prepare for the examination. He became more socially withdrawn than he had been in the previous year and spent all day at home for a year. A month before his hospitalization, he was admitted to a community college to study electrical engineering, but soon began to hear commanding voices of unknown origin telling him to

(a) This is an Open-Access article distributed under the terms of the Creative Commons Attribution Non-Commercial License (http://creativecommons.org/licenses/by-nc/3.0) which permits unrestricted non-commercial use, distribution, and reproduction in any medium, provided the original work is properly cited. 
"build a nuclear power station and save the world." At times, he felt that his head was being controlled by someone and often stood alone muttering to himself.

The patient scored 110 on the Positive and Negative Syndrome Scale (PANSS), ${ }^{7}$ and his severity subscore on the Clinical Global Impressions (CGI) scale was 6.

The initial diagnosis was schizophrenia. A pharmacological therapy based on the current treatment algorithm was initiated targeting auditory hallucination, delusion, autistic and aggressive behavior, and blunted affect.

In his first antipsychotic trial, olanzapine was administered across a low-, medium-, and high-dose range (titrated between 10 and $30 \mathrm{mg}$ ). However, 4 weeks after hospitalization and treatment onset, the constant, commanding hallucination persisted. Moreover, the patient had begun banging his head against the door and refused meals nearly every day. At that point, his PANSS score was 102, and only a slight clinical improvement was observed. Because of his poor treatment response to prior medication, the rising frequency and intensity of his self-injurious behavior, and the poor clinical outcome, it was necessary to switch his antipsychotic medication. A clozapine trial was started based on its high response and remission rates in first-episode schizophrenia. The patient and his family were fully informed about the benefits and possible adverse events associated with clozapine. All laboratory tests and electrocardiogram (EKG), electroencephalogram (EEG), and brain magnetic resonance imaging were within normal limits. No evidence of encephalopathy was found. Complete blood cell counts were monitored weekly during dose titration. Olanzapine treatment was discontinued, and we initiated clozapine at 25 $\mathrm{mg}$ and increased the dose to $200 \mathrm{mg}$ following the recommended dose titration schedule.

On day 60, the patient reported experiencing few auditory hallucinations and he began socializing with other patients. Moreover, he showed marked improvement in conceptual disorganization and bizarre content of thinking (PANSS score, 70). We observed no adverse side effects or physical compromise during the treatment regime. Three months after clozapine initiation, the patient was discharged from the hospital, and his psychopathology remained stable (PANSS score, 60).

The patient remains on a daily maintenance dose of clozapine $(200 \mathrm{mg})$, and he is living with his parents while working and continuing his college education. Despite residual emotional and passive social withdrawal, the patient accepts the necessity for treatment, which has prevented further psychiatric decompensation.

\section{DISCUSSION}

The initial tailoring of antipsychotic medication for a patient experiencing a first episode of psychosis is a critical empirical process with substantial and compelling consequences. ${ }^{8)}$ Our case supports the recommendation for earlier and more prolonged trials of clozapine to improve clinical outcome and lead to earlier and longer remission intervals. ${ }^{9)}$

Clozapine trials are often delayed longer than is clinically desirable. ${ }^{4)}$ Such hesitation may have a significant impact on the patient's quality of life, clinical outcome, and adherence to treatment. Preliminary data suggest that clozapine is most effective in the initial year of treatment in first-episode treatment-naive patients with schizophrenia. ${ }^{9)}$ Thus, for a higher response rate, clozapine should be considered as a second-line rather than a third-line treatment. Further analysis of the risk-benefit ratio in terms of potential side effects and individual patient psychopathology is essential.

\section{REFERENCES}

1. Royal Australian and New Zealand College of Psychiatrists Clinical Practice Guidelines Team for the Treatment of Schizophrenia and Related Disorders. Royal Australian and New Zealand College of Psychiatrists clinical practice guidelines for the treatment of schizophrenia and related disorders. Aust N Z J Psychiatry 2005;39:1-30.

2. Alphs LD, Anand R. Clozapine: the commitment to patient safety. J Clin Psychiatry 1999;60(Suppl 12):39-42.

3. Henderson DC, Nguyen DD, Copeland PM, Hayden DL, Borba CP, Louie PM, et al. Clozapine, diabetes mellitus, hyperlipidemia, and cardiovascular risks and mortality: results of a 10-year naturalistic study. J Clin Psychiatry 2005; 66:1116-1121.

4. Remington G, Agid O, Foussias G, Hahn M, Rao N, Sinyor M. Clozapine's role in the treatment of first-episode schizophrenia. Am J Psychiatry 2013;170:146-151.

5. Green AI, Schildkraut JJ. Should clozapine be a first-line treatment for schizophrenia? The rationale for a double-blind clinical trial in first-episode patients. Harv Rev Psychiatry 1995;3:1-9.

6. Lieberman J, Jody D, Geisler S, Vital-Herne J, Alvir JM, Walsleben $\mathrm{J}$, et al. Treatment outcome of first episode schizophrenia. Psychopharmacol Bull 1989;25:92-96.

7. Kay SR, Fiszbein A, Opler LA. The positive and negative syndrome scale (PANSS) for schizophrenia. Schizophr Bull 1987;13:261-276.

8. Freudenreich O, McEvoy JP. Optimizing outcome with antipsychotic treatment in first-episode schizophrenia: balancing efficacy and side effects. Clin Schizophr Relat Psychoses 2012;6:115-121.

9. Sanz-Fuentenebro J, Taboada D, Palomo T, Aragües M, Ovejero S, Del Alamo C, et al. Randomized trial of clozapine vs. risperidone in treatment-naïve first-episode schizophrenia: results after one year. Schizophr Res 2013;149:156-161. 